\title{
Inactive lifestyles and sedentary behavior in persons with chronic aneurysmal subarachnoid hemorrhage: evidence from accelerometer-based activity monitoring
}

Wouter J. Harmsen ${ }^{1,2^{*}}$, Gerard M. Ribbers ${ }^{1,2}$, Majanka H. Heijenbrok-Kal ${ }^{1,2}$, Johannes B. J. Bussmann ${ }^{1,2}$, Emiel M. Sneekes ${ }^{1,2}$, Ladbon Khajeh ${ }^{3}$, Fop van Kooten ${ }^{3}$, Sebastian J. C. M. M. Neggers ${ }^{4}$

and Rita J. van den Berg-Emons ${ }^{1,2}$

\begin{abstract}
Background: Aneurysmal subarachnoid hemorrhage (a-SAH) is a potential life-threatening stroke. Because survivors may be at increased risk for inactive and sedentary lifestyles,

this study evaluates physical activity (PA) and sedentary behavior (SB) in the chronic phase after a-SAH.

Methods: PA and SB were objectively measured at six months post a-SAH with an accelerometer-based activity monitor, with the aim to cover three consecutive weekdays. Total time spent in PA (comprising walking, cycling, running and non-cyclic movement) and SB (comprising sitting and lying) was determined. Also, in-depth analyses were performed to determine the accumulation and distribution of PA and SB throughout the day. Binary time series were created to determine the mean bout length and the fragmentation index. Measures of PA and SB in persons with a-SAH were compared to those in sex- and age-matched healthy controls.
\end{abstract}

Results: The 51 participants comprised 33 persons with a-SAH and 18 controls. None of the participants had signs of paresis or spasticity. Persons with a-SAH spent $105 \mathrm{~min} / 24 \mathrm{~h}$ being physically active, which was $35 \mathrm{~min} / 24 \mathrm{~h}$ less than healthy controls $(p=0.005)$. For PA, compared with healthy controls, the mean bout length was shorter in those with a-SAH (12.0 vs. $13.5 \mathrm{~s}, p=0.006)$ and the fragmentation index was higher $(0.053 \mathrm{vs} .0 .041, p<0.001)$. Total sedentary time during waking hours showed no significant difference between groups (514 min vs. 474 min, $p=0.291)$. For $S B$, the mean bout length was longer in persons with a-SAH (122.3 vs. $80.5 s, p=0.024)$, whereas there was no difference in fragmentation index between groups ( 0.0032 vs $0.0036, p=0.396$ ).

Conclusions: Persons with a-SAH are less physically active, they break PA time into shorter periods, and SB periods last longer compared to healthy controls. Since inactive lifestyles and prolonged uninterrupted periods of SB are independent risk factors for poor cardiovascular health, interventions seem necessary and should target both PA and SB.

Study registration: Dutch registry number: NTR 2085.

Keywords: Subarachnoid hemorrhage, Physical activity, Sedentary behavior, Fatigue, Rehabilitation, Stroke

\footnotetext{
* Correspondence: wharmsen@rijndam.nl

${ }^{1}$ Rijndam Rehabilitation Institute, Rotterdam, the Netherlands

2Department of Rehabilitation Medicine, Erasmus MC University Medical

Center Rotterdam, P.O. Box 2040, 3000, CA, Rotterdam, The Netherlands

Full list of author information is available at the end of the article
} 


\section{Background}

Aneurysmal subarachnoid hemorrhage (a-SAH) is defined by the extravasation of blood into the subarachnoid space, and is caused by a spontaneous bleeding of a ruptured brain aneurysm [1]. It accounts for $5 \%$ of all stroke cases and has an incidence rate of 9/100,000 persons/year and a mortality rate of $50 \%[1,2]$. Persons with a-SAH are relatively young compared with those with ischemic or hemorrhagic stroke (55 years vs. 70 years) [1, 3]. Further, whereas ischemic or hemorrhagic stroke may lead to focal brain injury with specific stroke-related symptoms, brain injury in a-SAH has a more diffuse character without typical stroke symptoms [1]. Those who survive are likely to experience long-term symptoms, such as cognitive problems (40\%), emotional complaints (50\%), depressive symptoms (40\%), and fatigue (up to 90\%) [4-7]. Even among those who are classified as having a 'favorable outcome', the incidence of clinical deficits is high [8].

Persons with a-SAH seem to have difficulty with resuming their daily activities, and only one-third is able to fully resume their previous occupation [4, 9]. The inability to perform daily activities is associated with passive coping styles, depressive symptoms and fatigue [6, 8-10]. Reduced physical fitness after a-SAH has been reported, [11]. which may also hinder the performance of daily activities. Therefore, individuals with a-SAH may be at risk of inactive and sedentary lifestyles, placing them at risk for poor health outcomes [12-14]. However, measures of daily PA and SB have not yet been studied after a-SAH.

PA refers to 'any bodily movement produced by skeletal muscles that requires energy expenditure' and contributes to the primary and secondary prevention of chronic diseases, including cardiovascular disease, cancer, diabetes mellitus, hypertension and obesity $[15,16]$. SB, defined as a distinct class of activities that requires low levels of energy expenditure and involves sitting and lying activities during waking hours, negatively impacts metabolism and cardiovascular health [17, 18]. Recent studies show that SB impacts cardiovascular health, independent of the volume of PA [18]. Furthermore, not only the total volume of PA or SB, but also the way PA and SB are accumulated is important, i.e. prolonged bouts of PA are beneficial, whereas prolonged bouts of SB are found to be detrimental to cardiovascular health [18-21].

Persons with stroke not caused by a-SAH are highly sedentary, with PA levels almost half that of healthy control subjects [22-24]. In stroke rehabilitation, improving PA and SB is strongly recommended, as it provides protective benefits in the primary and secondary prevention of chronic diseases $[16,25]$. Inactive and sedentary lifestyles in ischemic or hemorrhagic stroke have been frequently explained by motor impairments following neuro-motor lesions. Since brain injury in a-SAH is more diffuse without typical stroke symptoms (such as paresis), it would be of interest to gain insight in the level of PA and SB in this patient group.

Despite its importance, PA and SB have not yet been studied in persons with a-SAH. Therefore, this study evaluates $\mathrm{PA}$ and $\mathrm{SB}$ in the chronic phase after a-SAH. Objectively obtained measures of PA and SB were compared to those in sex- and age-matched healthy controls. This study can help to optimize recommendations to prevent chronic diseases and debilitating conditions after a-SAH, but can also be used to better understand the consequences of different types of stroke on daily PA and SB. Since individuals with a-SAH have difficulty in resuming their daily activities and have reduced physical fitness, we hypothesized that they would be less physically active and more sedentary compared to healthy controls.

\section{Methods \\ Participants and study design}

The present study (entitled HIPS-Rehab) was part of the 'Hypopituitarism In Patients after Subarachnoid hemorrhage (HIPS) study' [26]. In this study we investigate the PA and SB of persons who were six months post a-SAH. Participants with a-SAH admitted to the department of Neurology of Erasmus University MC were eligible for inclusion if they were aged $\geq 18$ years. Diagnosis of a-SAH was confirmed by computerized tomography $(\mathrm{CT})$ of the brain and, in cases with negative $\mathrm{CT}$, by lumbar puncture. Exclusion criteria were: hypothalamic or pituitary disease diagnosed prior to a-SAH, history of cranial irradiation, trauma capitis prior to a-SAH, other intracranial lesion apart from a-SAH, and other medical or psychiatric condition or laboratory abnormality that may interfere with the outcome of the study. Participants were also excluded if they were aged $\geq 70$ years. For comparison, we included healthy controls of similar sex (\% females; 64 vs. $72 \%, p=0.382$ ) and age (52.6 vs. 51.0 years, $p=0.548$ ). Healthy controls were recruited by advertisement; they wore identical activity monitors and similar measurement procedures were applied.

The study was approved by the Medical Ethics Committee of Erasmus University Medical Centre, and all participants provided written informed consent.

\section{Physical activity and sedentary behavior}

PA and SB were objectively measured with an accelerometer-based activity monitor (VitaMove) ${ }^{1}$ (Fig. 1). This monitor has demonstrated validity for quantifying body postures and movements in healthy subjects and in different patient groups [27-29]. The VitaMove activity 


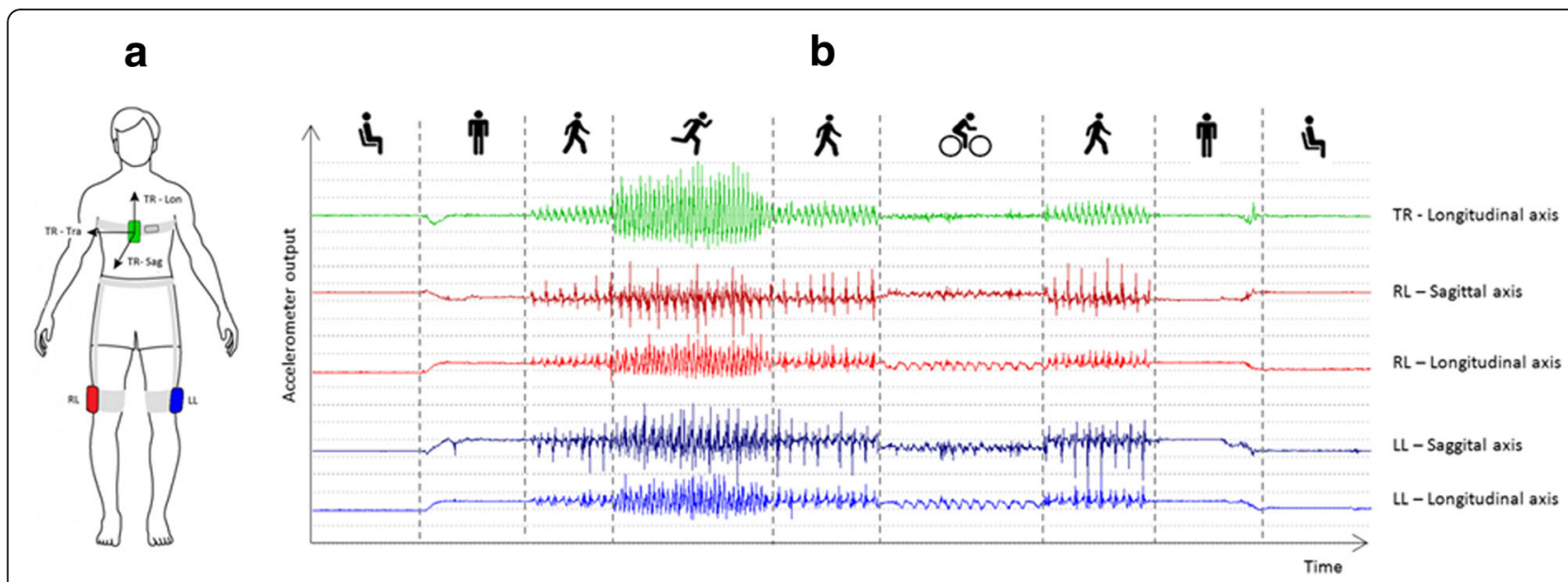

Fig. 1 Placement of the VitaMove activity monitor is shown in (a), and a typical output derived from the raw accelerometer signals is presented in (b). The pattern of these signals determines the corresponding activity. A sequence of activities is presented: sitting, standing, walking, running,

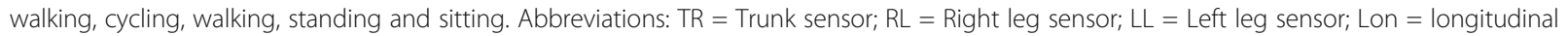
axis; Sag = sagittal axis; Tra $=$ transversal axis

monitor consists of three individual body-fixed recorder units, which are wirelessly connected and synchronized every $10 \mathrm{~s}$. One recorder unit was attached to the trunk (sternum position) and one to each thigh, using specially developed elastic belts. Each unit has its own tri-axial accelerometer, ${ }^{2}$ power supply and storage capacity. Participants wore the VitaMove on consecutive weekdays, except during swimming, bathing and sleeping. In line with previous research, the intended duration of measurement was three consecutive days, with a minimum of one day $[30,31]$. Further, the signal processing parameters were identical to the parameter settings used in previous validity studies [27-29]. Mean values were calculated for multiple days of activity monitoring. Participants were instructed to continue their ordinary daily activities. The principles of the measurements were explained after all measurements were completed in order to avoid measurement bias. In addition, participants kept activity diaries to report reasons of non-wear periods of the activity monitor.

\section{Data processing}

Accelerometer signals of each recorder unit were continuously measured and stored $(128 \mathrm{~Hz})$ on a micro Secure Digital memory card. Accelerometer signals were downloaded on a computer for kinematic analyses using specially developed VitaScore software. ${ }^{3}$ Waking hours were determined by the researcher $(\mathrm{WH})$ using the diaries filled out by the participants and by inspection of the raw data signals; specifically, ongoing flatlines indicate that the recorder units were taken off, reflecting the end of waking hours. Body postures and movements (e.g. lying, sitting, standing, walking, cycling, running and non-cyclic movements) were automatically detected with a 1-s time resolution from the feature time series (i.e. angle, frequency and motility) derived from the measured accelerometer signals. The motility feature expresses the intensity of the movement of the body segment to which the unit is attached, and depends on the variability of the acceleration signal; motility can be compared to counts that are calculated in regular activity monitors (calculated in gravitational force (g), $\left.1 \mathrm{~g}=9.81 \mathrm{~m} / \mathrm{s}^{2}\right)$. During walking, the body motility signal (i.e. the mean of the leg and trunk motility signals) corresponds to walking speed [32]. The minimum duration threshold for each activity was $5 \mathrm{~s}$. A detailed description of the algorithms and analysis is published elsewhere [28, 30].

In-depth analyses were performed to quantify the accumulation and distribution metrics of PA and SB. For PA outcomes, the four detected body movements (walking, cycling, running, and non-cyclic movements) were categorized into one PA category; a similar procedure was followed for the SB category, covering lying and sitting activities. Binary time series of PA (yes $=1$, no $=0$ ) and $\mathrm{SB}$ (yes $=1$, no $=0$ ) were created using custommade Matlab algorithms. A period of uninterrupted samples of either PA (or SB) was classified as a bout. Due to the minimum duration threshold of $5 \mathrm{~s}$, bouts and periods between bouts lasted at least $5 \mathrm{~s}$.

\section{Outcome measures}

\section{Volume, intensity and distribution of $P A$ and $S B$}

To determine the volume of PA, we calculated the total time spent in the four detected body movements during waking hours. The volume of total SB was determined by evaluating the total time of sitting and lying activities during the waking hours. Volume measures were then expressed as a percentage of a $24 \mathrm{~h}$ period, and as a 
percentage of waking hours. The mean motility of PA and the mean motility of walking were also determined and expressed in $\mathrm{g}$.

The binary time series were used to determine the accumulation and distribution of PA and SB. The total number of bouts and the mean bout length (in seconds) were calculated. Since the mean bout length was not normally distributed, the natural logarithm was taken. The mean log length was back transformed to the original scale. The fragmentation index was calculated and reflects the ratio between the number of PA (or SB) bouts divided by the total PA (or SB) time [33]. A higher fragmentation index indicates that total PA (or SB) time is more fragmented, which means that there are less prolonged periods of PA (or SB) [34].

\section{Participants' characteristics}

At hospital intake, the following Clinical characteristics were obtained including: 1) the severity of a-SAH according to the grading of the World Federation of Neurologic Surgeons (low-grade: I-III or high-grade: IVV) $[35,36]$ and the Glasgow Coma Scale (GCS) score, [37] 2) location of the aneurysm (anterior or posterior circulation), 3) treatment procedure (surgical clipping or endovascular treatment), 4) presence of secondary health complications (re-bleed, delayed cerebral ischemia, hyponatremia, hydrocephalus and growth hormone deficiency; defined as an insufficient growth hormone $(\mathrm{GH})$ response to a $\mathrm{GH}$-releasing hormone -arginine test), [38] and 5) neurologic comorbidity (paresis or spasticity). Neurologic morbidity (such as paresis or spasticity) was evaluated by treating neurologist. Information on the following characteristics and body anthropometrics were collected from both groups: sex, age, weight, height and Body Mass Index (BMI).

\section{Statistical analysis}

All data are expressed as mean (SD) unless otherwise indicated. To compare the clinical characteristics between participants of HIPS-Rehab and those who did not participate (but were included in HIPS), we used independent t-tests for continuous data and chi-square-tests for categorical data. To compare the characteristics and measures of PA and SB between individuals with a-SAH and controls, independent t-tests were applied for continuous data and chi-square tests for categorical data. All analyses were performed using IBM SPSS Statistics, version $20{ }^{4}$ A probability value of $p<0.05$ was considered statistically significant.

\section{Results}

Of the 241 patients admitted to the ICU with a diagnosis of a-SAH, 84 were included in HIPS of which 52 volunteered to participate in HIPS-Rehab. Participants in
HIPS-Rehab $(n=52)$ did not differ from those who did not participate (but were included in HIPS; $n=32$ ) regarding the severity of a-SAH, location of the aneurysm, treatment procedure, and the presence of secondary health complications. Of the 52 participants, successful activity monitoring measurements were obtained from 33: of the 19 unsuccessful attempts, 6 refused to wear the activity monitor, in 4 persons data processing was unsuccessful due to technological failure, and 9 were aged $\geq 70$ years (Fig. 2 ).

Table 1 presents the clinical characteristics. Most persons underwent endovascular coiling (82\%) and had a ruptured aneurysm in the anterior circulation (61\%). The neurological scores showed that 29 participants had a low-grade a-SAH (88\%) and a mean GCS score of 14.0 (SD 2.0). None of the participants had a paresis or showed signs of spasticity.

Due to challenges with activity monitoring, data were not available for all participants for the intended three days of measurement. The duration of measurement was 3 days in $42 \%$ of those with a-SAH and in $83 \%$ of the controls; 2 days in $48 \%$ of those with a-SAH and in $6 \%$ of the controls; and 1 day in $9 \%$ of the persons with a$\mathrm{SAH}$ and in $11 \%$ of the controls. Mean daily wear time did not differ between the groups, $13.7 \mathrm{~h}$ (SD $1.8)$ vs. $14.1 \mathrm{~h}$ (SD 1.3), respectively, (95\% CI of the difference: $-1.4 \mathrm{~h}$ to $0.5 \mathrm{~h} ; p=0.372$ ).

Table 2 presents the characteristics of the two groups: persons with a-SAH did not differ from healthy controls regarding sex $(p=0.382)$, age $(p=0.548)$, weight $(p=0.231)$ and height $(p=0.062)$, but had a higher BMI $(p=0.002)$. Table 2 also presents the volume measures of $\mathrm{PA}$ and $\mathrm{SB}$ in the two groups. Persons with a-SAH spent $105 \mathrm{~min} / 24 \mathrm{~h}(=7.3 \%)$ being physically active, which is $35 \mathrm{~min} / 24 \mathrm{~h}(2.4 \%)$ less compared with that of healthy controls $(140 \mathrm{~min} / 24 \mathrm{~h}(=9.7 \%) ; p=0.005)$; in particular, there was less participation in cycling activities (3 $\mathrm{min} / 24 \mathrm{~h}(=0.2 \%)$ vs. $27 \mathrm{~min} / 24 \mathrm{~h}(=1.9 \%)$; $p<0.001)$. Total sedentary time did not differ between those with a-SAH and healthy controls; $514 \mathrm{~min} / 24 \mathrm{~h}$ $(=35.7 \%)$ vs. $473 \mathrm{~min} / 24 \mathrm{~h}(=32.9 \%$; $p=0.291)$, respectively. Also, there was no difference between the groups in total standing time, i.e. $200 \mathrm{~min} / 24 \mathrm{~h}(=13.9 \%)$ vs. $233 \mathrm{~min} / 24 \mathrm{~h}(=16.2 \%, p=0.164)$, or in mean PA motility and mean walking motility $(p=0.442$ and $p=0.503$, respectively).

Mean bout length of PA in persons with a-SAH was shorter than in controls (12.0 s vs. $13.5 \mathrm{~s} ; p=0.006)$, and the PA fragmentation index was higher (0.053 vs. $0.041 ; p<0.001)$, indicating that the PA periods were shorter and the total time spent in PA was more fragmented in persons with a-SAH. Mean bout length of SB was longer in persons with a-SAH $(122.3 \mathrm{~s}$ vs. $80.5 \mathrm{~s}$; $p=0.024)$, whereas the SB fragmentation index did not 


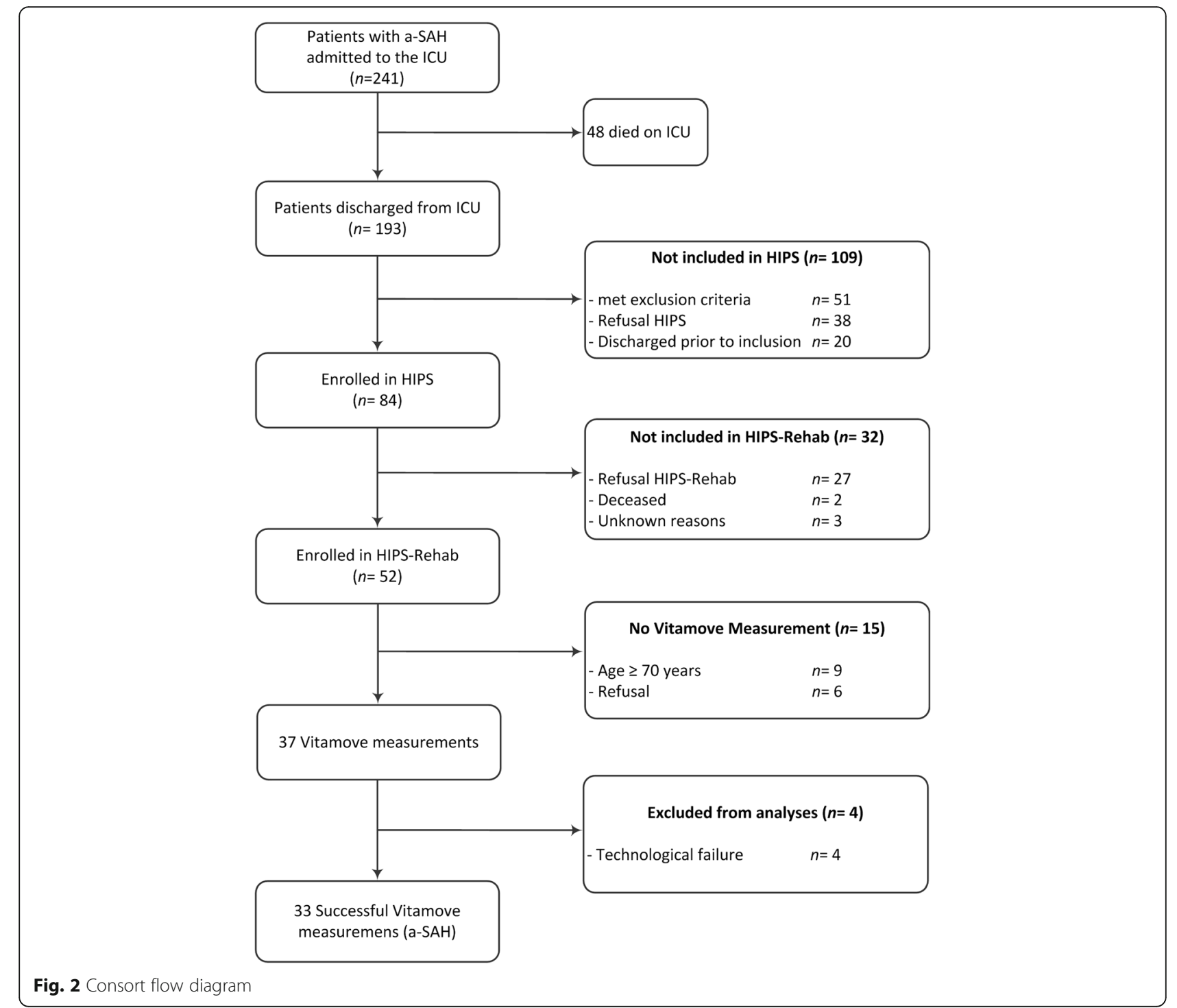

differ between groups $(p=0.396)$. This indicates that SB periods lasted longer in persons with a-SAH, but the way in which the total SB was distributed did not differ between groups (Table 3).

\section{Discussion}

The present study shows that persons with a-SAH are less physically active, they break PA time into shorter periods, and SB periods last longer compared to healthy controls, placing them at increased risk for poor health outcomes [12-14]. This is the first study on PA and SB in persons with a-SAH. The objectively obtained measures of PA and SB have meaningful implications for stroke rehabilitation because our findings reveal that inactive and sedentary lifestyles are present in absence of motor impairments. Given the importance of optimal PA and SB, $[21,22]$ therapeutic interventions are warranted. The present findings may help to improve interventions (targeting both PA and SB) and prevent debilitating conditions after a-SAH.

In-depth analysis of PA revealed that persons with aSAH break their PA time into shorter periods, which is not beneficial from a health perspective [21]. These interruptions may be explained by an increased number of moments of rest, possibly related to higher fatigability, cognitive dysfunction, and/or lower cardiorespiratory fitness $[5,7]$. The most recent guidelines of the WHO recommend an accumulation of PA time, i.e. uninterrupted $\mathrm{PA}$, of at least $10 \mathrm{~min}$, as this is an important aspect of healthy PA [39]. Therefore, therapeutic interventions should not only target the total volume of PA, but should also improvethe accumulation of PA time in persons with a-SAH.

Sedentary time, particularly accumulated in long uninterrupted periods, negatively impact cardiovascular health, independent of the volume of PA [18]. In-depth 
Table 1 Descriptive characteristics

\begin{tabular}{ll}
\hline Characteristics & Participants with a-SAH $(n=33)$ \\
\hline Sex, female, $n$ (\%) & $21(64 \%)$ \\
Age (years), mean (SD) & $52.6(9.0)$ \\
WFNS grade, $n$ (\%) & $16(48 \%)$ \\
I & $13(39 \%)$ \\
III & $1(3 \%)$ \\
IV & $3(9 \%)$ \\
V & 0 \\
Glasgow Coma Scale score, mean (SD) & $14.0(2.0)$ \\
Location aneurysm, $n$ (\%) & \\
Anterior circulation & $20(61 \%)$ \\
Posterior circulation & $13(39 \%)$ \\
Aneurysm treatment, $n$ (\%) & \\
Endovascular treatment ${ }^{\mathrm{a}}$ & $27(82 \%)$ \\
Surgical clipping & $6(18 \%)$ \\
Re-bleed, $n$ (\%) & 0 \\
Delayed cerebral ischemia, $n(\%)$ & $7(21 \%)$ \\
Hyponatremia, $n$ (\%) & $4(12 \%)$ \\
Hydrocephalus, $n$ (\%) & $9(27 \%)$ \\
Growth Hormone Deficient, $n(\%)$ & $2(6 \%)$ \\
\hline A &
\end{tabular}

Abbreviations: WFNS grade World Federation of Neurologic Surgeons grading system for subarachnoid hemorrhage

${ }^{a}$ Endovascular treatment is also known as endovascular coiling

analysis of SB revealed that SB periods lasted longer in persons with a-SAH. However, the SB fragmentation index did not differ, indicating that the way total $\mathrm{SB}$ is distributed in a-SAH is similar to that in healthy controls. This could be explained by the fact that the total sedentary time was somewhat higher (albeit not significant) in a-SAH than in healthy controls. Since SB periods lasted longer in those with a-SAH than in controls, breaking prolonged uninterrupted SB periods may represent another therapeutic target in order to provide additional health benefits in persons with a-SAH.

In patients with stroke not caused by a-SAH, the most commonly used objective measures of PA are step or activity counts per day; these counts are reported to be almost half those of healthy controls [22-24]. The present study explored activity profiles beyond simple step or activity counts and distinguished different types of PA. Overall, persons with a-SAH spent $25 \%$ less time in PA than healthy controls (105 vs $140 \mathrm{~min} / 24 \mathrm{~h}$, respectively). However, the total volume of walking activities did not differ between groups; this is in line with an accelerometerbased study on walking activities in patients with stroke [40]. Furthermore, compared with controls, persons with a-SAH participated particularly less in cycling activities and, to a lesser extent, in running activities.
Interestingly, physically inactive and sedentary lifestyles after a-SAH seem not be related to motor impairments, and therefore other mechanisms should underlie our findings. For example, PA may be limited by impaired cardiorespiratory fitness, cognitive dysfunction, anxiety or fatigue. Feelings of anxiety after a-SAH can highly restrict participation in daily activities [41, 42]. Furthermore, PA can also be limited by concentration problems, [5, 43, 44] e.g. cycling activities are more demanding due to participation in traffic and multitasking. However, future studies are warranted to investigate the barriers and facilitators of PA after a-SAH, and should take into account mechanisms of physical deconditioning, cognitive dysfunction, anxiety and fatigue.

In persons with a-SAH, total sedentary time during waking hours was $514 \mathrm{~min}$. This is similar to findings in persons with stroke, not caused by a-SAH (i.e. sedentary times ranging from 464 to $654 \mathrm{~min}$ ) [23, 24]. This is remarkable because patients with a non a-SAH stroke are often older and more restricted in the performance of daily activities (often because of neurological deficits) than patients with a-SAH $[1,6]$. With regard to $\mathrm{SB}$, there are no guidelines for the general population. A metaanalysis showed that above $7.0 \mathrm{~h}$, every additional hour increase in SB time is associated with a $5 \%$ increase in all-cause mortality [45]. In the present study, individuals with a-SAH spent about $8.5 \mathrm{~h}$ being sedentary, implying a $7.5 \%$ increase in all-cause mortality. In order to set therapeutic targets, additional studies are needed to establish guidelines for SB.

The major strength of the present study is the objective measurement of $\mathrm{PA}$ and $\mathrm{SB}$, without possible bias from the subjective character of a questionnaire. Also, the inclusion of healthy controls allowed us to better interpret the data. Another strength is that we used innovative in-depth analyses of PA and SB which provides new insights to support future therapeutic interventions.

\section{Study limitations}

Some limitations of the present study should be discussed. First, we used an advanced activity monitor that allowed to obtain continuous data on various types of $\mathrm{PA}$ and SB. However, this makes it difficult to compare our data with general guidelines for healthy PA or SB, because these guidelines are mostly based on self-report questionnaires [29]. Future studies need to define guidelines for healthy PA and SB, based on objectively obtained measures. Second, for logistic reasons, the sample size of healthy controls was smaller compared to that in persons with a-SAH. Smaller number of controls have been frequently reported in activity monitoring research across different patient groups, including stroke [46, 47]. Overall, results on the main outcome (volume metrics) 
Table 2 Characteristics and results of activity monitoring measurement

\begin{tabular}{|c|c|c|c|c|}
\hline & Participants with a-SAH $(n=33)$ & Healthy controls $(n=18)$ & $95 \% \mathrm{Cl}$ of the difference & $p$-value \\
\hline Sex, females, $n(\%)$ & $21(64 \%)$ & $13(72 \%)$ & & 0.382 \\
\hline Age (years) & $52.6(9.0)$ & $51.0(8.6)$ & -3.7 to 6.8 & 0.548 \\
\hline Weight (kg) & $75.6(13.0)$ & $71.4(9.1)$ & -2.7 to 11.1 & 0.231 \\
\hline Height (m) & $1.67(0.1)$ & $1.72(0.1)$ & -11.7 to 0.3 & 0.062 \\
\hline Body Mass Index $\left(\mathrm{kg} / \mathrm{m}^{2}\right)$ & $27.1(3.8)$ & $23.9(2.0)$ & 1.2 to 4.7 & 0.002 \\
\hline \multicolumn{5}{|l|}{ Activity profiles $^{a}$} \\
\hline \% Physical activity & $7.3(3.0)$ & $9.7(2.1)$ & -3.9 to -0.8 & 0.005 \\
\hline - \% Walking & $4.7(2.4)$ & $4.7(1.3)$ & -1.2 to 1.3 & 0.964 \\
\hline - \% Cycling & $0.2(0.4)$ & $1.9(1.7)$ & -2.3 to -1.1 & $<0.001$ \\
\hline - \% Running & $0.0(0.0)$ & $0.1(0.3)$ & -0.2 to -0.02 & 0.018 \\
\hline - \% Non-cyclic movement & $2.4(1.7)$ & $3.0(1.1)$ & -1.5 to 0.3 & 0.200 \\
\hline$\%$ Standing & $13.9(5.4)$ & $16.2(5.7)$ & -5.6 to 1.0 & 0.164 \\
\hline$\%$ Sedentary behavior & $35.7(9.9)$ & $32.9(7.6)$ & -2.5 to 8.3 & 0.291 \\
\hline - \% Sitting & $32.5(10.1)$ & $30.7(7.7)$ & -3.6 to 7.3 & 0.502 \\
\hline - \% Lying & $3.2(3.5)$ & $2.2(1.8)$ & -0.8 to 2.8 & 0.253 \\
\hline$\%$ Non-wear ${ }^{b}$ & $43.0(7.3)$ & $41.2(5.6)$ & -2.2 to 5.8 & 0.372 \\
\hline \multicolumn{5}{|l|}{ Intensity meausures } \\
\hline Motility physical activity $(\mathrm{g})^{c}$ & $45.6(11.9)$ & $47.8(8.6)$ & -7.5 to 3.3 & 0.442 \\
\hline Motility walking $(\mathrm{g})^{c}$ & $37.6(9.9)$ & $39.7(7.7)$ & -8.6 to 4.3 & 0.503 \\
\hline
\end{tabular}

Duration of activities as a percentage of $24 \mathrm{~h}$

aphysical behavior was monitored on consecutive weekdays in the free-living situation

${ }^{\mathrm{b}}$ Non-wear = time that participants did not wear the activity monitor (also reflects nighttime)

$c_{\mathrm{g}}=$ gravitational forces $* 100$

in the controls are comparable with, and for PA even somewhat lower ( $9.7 \%$ vs $10-12 \%$ per $24 \mathrm{~h}$, respectively) than results, as measured with the VitaMove, in other healthy comparison groups [48-50]. This difference may even indicate that we have underestimated the lack of $\mathrm{PA}$ in persons with a-SAH. BMI was somewhat higher in persons with a-SAH than in controls. However, it was not feasible to account for BMI, as a higher BMI may already be indicative of physically inactive and sedentary lifestyles. Another limitation is that, in both groups, actually 'wearing' the activity monitor may have influenced PA in daily life; nevertheless, all participants reported that they performed their regular PA. Another limitation is that we did not include any physiological parameters (e.g. heart rate) that might have provided more details on physical strain of PA in daily life.

\section{Conclusions}

Objectively obtained measures of PA and SB show that persons with a-SAH are less physically active, they break PA time into shorter periods, and SB periods last longer compared to healthy controls. These results suggest that persons with a-SAH have increased health risks related to inactive lifestyles and sedentary lifestyles. Given the importance of optimal $\mathrm{PA}$ and $\mathrm{SB}$, future studies need to identify barriers

Table 3 Distribution of physical activity and sedentary behavior

\begin{tabular}{|c|c|c|c|c|}
\hline & Participants with a-SAH $(n=33)$ & Controls $(n=18)$ & $95 \% \mathrm{Cl}$ of the difference & $p$-value \\
\hline \multicolumn{5}{|l|}{ Physical activity } \\
\hline Mean bout length $(s)^{a}$ & $12.0(1.9)$ & $13.5(1.2)$ & -2.4 to -0.4 & 0.006 \\
\hline Fragmentation index ${ }^{b}$ & $0.053(0.01)$ & $0.041(0.01)$ & 0.006 to 0.019 & $<0.001$ \\
\hline \multicolumn{5}{|l|}{ Sedentary Behavior } \\
\hline Mean bout length $(s)^{a}$ & $122.3(71.5)$ & $80.5(35.6)$ & 5.6 to 78.0 & 0.024 \\
\hline Fragmentation index ${ }^{\mathrm{b}}$ & $0.0032(0.002)$ & $0.0036(0.002)$ & -0.001 to 0.001 & 0.396 \\
\hline
\end{tabular}

The minimum bout length lasted at least $5 \mathrm{~s}$

aninterrupted bouts with a minimum length of $5 \mathrm{~s}$

${ }^{\mathrm{b}}$ Fragmentation index represents the ratio between the number of sedentary bouts divided by the total time being sedentary 
and facilitators of PA and SB to develop optimal therapeutic interventions to improve $\mathrm{PA}$ and $\mathrm{SB}$ after a-SAH.

\section{Endnotes}

${ }^{1}$ Activity Monitor, VitaMove, 2 M Engineering, Veldhoven, the Netherlands

${ }^{2}$ Accelerometer, Freescale MMA7260Q, Denver, USA

${ }^{3}$ Activity monitor software, VitaScore BV, Gemert, the Netherlands

${ }^{4}$ SPSS Inc., Chicago, IL, USA

\section{Acknowledgements}

Not applicable.

\section{Funding}

Financial support for this study was provided by the Dutch Brain Foundation (grant no. 15F07.06)

\section{Availability of data and materials}

The dataset used and/or analyzed during the current study available from the corresponding author on reasonable request.

\section{Authors' contributions}

$\mathrm{WH}$ contributed to the data collection, data analysis and drafting of the manuscript; GR and RB contributed to the design, data analysis, data interpretation and drafting of the manuscript; $\mathrm{MH}$ contributed to the design, statistical analysis and manuscript review; JB contributed to the interpretation of the data and manuscript review; ES contributed to the data collection, data analysis and manuscript review; LK, FK and SN contributed to the design, data interpretation and manuscript review. All authors read and approved the final manuscript.

\section{Ethics approval and consent to participate}

The present study was approved by the Medical Ethics Committee of Erasmus Medical Centre (Dutch Registry: NTR 2085). All participants provided written informed consent in accordance with ethical guidelines.

\section{Competing interest}

The authors declare that they have no competing interests.

\section{Publisher's Note}

Springer Nature remains neutral with regard to jurisdictional claims in published maps and institutional affiliations.

\section{Author details}

${ }^{1}$ Rijndam Rehabilitation Institute, Rotterdam, the Netherlands. 'Department of Rehabilitation Medicine, Erasmus MC University Medical Center Rotterdam, P.O. Box 2040, 3000, CA, Rotterdam, The Netherlands. ${ }^{3}$ Department of Neurology, Erasmus MC University Medical Center Rotterdam, Rotterdam, the Netherlands. ${ }^{4}$ Department of Endocrinology, Erasmus MC University Medica Center Rotterdam, Rotterdam, the Netherlands.

Received: 7 November 2016 Accepted: 31 October 2017

Published online: 23 November 2017

References

1. van Gijn J, Kerr RS, Rinkel GJ. Subarachnoid haemorrhage. Lancet. 2007:369(9558):306-18

2. Rinkel GJ, Algra A. Long-term outcomes of patients with aneurysmal subarachnoid haemorrhage. Lancet Neurol. 2011:10(4):349-56.

3. Shive I. Age of onset for stroke delayed in the 21st century: what is next? Clin Neurol Neurosurg. 2011:113(9):725-6.

4. Passier PE, Visser-Meily JM, Rinkel GJ, Lindeman E, Post MW. Life satisfaction and return to work after aneurysmal subarachnoid hemorrhage. J Stroke Cerebrovasc Dis. 2011;20(4):324-9.
5. Boerboom W, Heijenbrok-Kal MH, Khajeh L, van Kooten F, Ribbers GM. Longterm functioning of patients with aneurysmal subarachnoid hemorrhage: a 4yr follow-up study. Am J Phys Med Rehabil. 2016;95(2):112-20.

6. Al-Khindi T, Macdonald RL, Schweizer TA. Cognitive and functional outcome after aneurysmal subarachnoid hemorrhage. Stroke. 2010:41(8):e519-36.

7. Kutlubaev MA, Barugh AJ, Mead GE. Fatigue after subarachnoid haemorrhage: a systematic review. J Psychosom Res. 2012;72(4):305-10.

8. Carter BS, Buckley D, Ferraro R, Rordorf G, Ogilvy CS. Factors associated with reintegration to normal living after subarachnoid hemorrhage. Neurosurgery 2000:46(6):1326-1333; discussion 33-4

9. Buunk AM, Groen RJ, Veenstra WS, Spikman JM. Leisure and social participation in patients 4-10 years after aneurysmal subarachnoid haemorrhage. Brain Inj. 2015;29(13-14):1589-96.

10. Vilkki J, Juvela S, Malmivaara K, Siironen J, Hernesniemi J. Predictors of work status and quality of life 9-13 years after aneurysmal subarachnoid hemorrahage. Acta Neurochir. 2012;154(8):1437-46.

11. Harmsen WJ, Ribbers GM, Zegers B, Sneekes EM, Heijenbrok-Kal MH, Khajeh $L$, et al. Impaired cardiorespiratory fitness after aneurysmal subarachnoid hemorrhage. J Rehabil Med. 2016;

12. Larsen RN, Kingwell BA, Sethi P, Cerin E, Owen N, Dunstan DW. Breaking up prolonged sitting reduces resting blood pressure in overweight/obese adults. Nutr Metab Cardiovasc Dis. 2014;24(9):976-82

13. Owen N, Healy GN, Matthews CE, Dunstan DW. Too much sitting: the population health science of sedentary behavior. Exerc Sport Sci Rev. 2010;38(3):105-13.

14. van der Ploeg HP, Chey T, Korda RJ, Banks E, Bauman A. Sitting time and all-cause mortality risk in 222497 Australian adults. Arch Intern Med. 2012;172(6):494-500

15. Caspersen CJ, Powell KE, Christenson GM. Physical activity, exercise, and physical fitness: definitions and distinctions for health-related research. Public Health Rep. 1985:100(2):126-31.

16. Warburton DE, Nicol CW, Bredin SS. Health benefits of physical activity: the evidence. CMAJ. 2006:174(6):801-9.

17. Thorp AA, Owen N, Neuhaus M, Dunstan DW. Sedentary behaviors and subsequent health outcomes in adults a systematic review of longitudinal studies, 1996-2011. Am J Prev Med. 2011;41(2):207-15.

18. Hamilton MT, Healy GN, Dunstan DW, Zderic TW, Owen N. Too little exercise and too much sitting: inactivity physiology and the need for new recommendations on sedentary behavior. Curr Cardiovasc Risk Rep. 2008:2(4):292-8

19. Healy GN, Dunstan DW, Salmon J, Cerin E, Shaw JE, Zimmet PZ, et al. Breaks in sedentary time: beneficial associations with metabolic risk. Diabetes Care. 2008;31(4):661-6.

20. Healy GN, Matthews CE, Dunstan DW, Winkler EA, Owen N. Sedentary time and cardio-metabolic biomarkers in US adults: NHANES 2003-06. Eur Heart J. 2011:32(5):590-7.

21. Pate RR, Pratt M, Blair SN, Haskell WL, Macera CA, Bouchard C, et al. Physical activity and public health. A recommendation from the Centers for Disease Control and Prevention and the American College of Sports Medicine. JAMA. 1995:273(5):402-7.

22. English C, Manns PJ, Tucak C, Bernhardt J. Physical activity and sedentary behaviors in people with stroke living in the community: a systematic review. Phys Ther. 2014;94(2):185-96.

23. Alzahrani MA, Ada L, Dean CM. Duration of physical activity is normal but frequency is reduced after stroke: an observational study. J Physiother. 2011;57(1):47-51.

24. English C, Healy GN, Coates A, Lewis L, Olds T, Bernhardt J. Sitting and activity time in people with stroke. Phys Ther. 2016:96(2):193-201.

25. Billinger SA, Arena R, Bernhardt J, Eng JJ, Franklin BA, Johnson CM, et al. Physical activity and exercise recommendations for stroke survivors: a statement for healthcare professionals from the American Heart Association/American Stroke Association. Stroke. 2014:45(8):2532-53

26. Khajeh L, Blijdorp K, Heijenbrok-Kal MH, Sneekes EM, van den Berg-Emons $\mathrm{HJ}$, van der Lely AJ, et al. Pituitary dysfunction after aneurysmal subarachnoid haemorrhage: course and clinical predictors-the HIPS study. I Neurol Neurosurg Psychiatry. 2014:

27. Nooijen CF, de Groot JF, Stam HJ, van den Berg-Emons RJ, Bussmann HB. Validation of an activity monitor for children who are partly or completely wheelchair-dependent. J Neuroeng Rehabil. 2015;12:11. 
28. Bussmann JB, Martens WL, Tulen JH, Schasfoort FC, van den Berg-Emons HJ, Stam HJ. Measuring daily behavior using ambulatory accelerometry: the activity monitor. Behav Res Methods Instrum Comput. 2001:33(3):349-56.

29. van den Berg-Emons RJ, L'Ortye AA, Buffart LM, Nieuwenhuijsen C, Nooijen CF, Bergen MP, et al. Validation of the physical activity scale for individuals with physical disabilities. Arch Phys Med Rehabil. 2011;92(6):923-8.

30. Nooijen CF, Slaman J, Stam HJ, Roebroeck ME, Berg-Emons RJ. Learn2Move research $\mathrm{G}$. Inactive and sedentary lifestyles amongst ambulatory adolescents and young adults with cerebral palsy. J Neuroeng Rehabil. 2014;11:49.

31. Russchen HA, Slaman J, Stam HJ, van Markus-Doornbosch F, van den Berg-Emons RJ, Roebroeck ME, et al. Focus on fatigue amongst young adults with spastic cerebral palsy. J Neuroeng Rehabil. 2014;11:161.

32. Serra MC, Balraj E, DiSanzo BL, Ivey FM, Hafer-Macko CE, Treuth MS, et al. Validating accelerometry as a measure of physical activity and energy expenditure in chronic stroke. Top Stroke Rehabil. 2016:1-6.

33. Chastin SF, Granat MH. Methods for objective measure, quantification and analysis of sedentary behaviour and inactivity. Gait Posture. 2010;31(1):82-6.

34. Tieges Z, Mead G, Allerhand M, Duncan F, van Wijck F, Fitzsimons C, et al. Sedentary behavior in the first year after stroke: a longitudinal cohort study with objective measures. Arch Phys Med Rehabil. 2015;96(1):15-23.

35. Sarrafzadeh A, Haux D, Kuchler I, Lanksch WR, Unterberg AW. Poor-grade aneurysmal subarachnoid hemorrhage: relationship of cerebral metabolism to outcome. J Neurosurg. 2004;100(3):400-6.

36. Teasdale GM, Drake CG, Hunt W, Kassell N, Sano K, Pertuiset B, et al. A universal subarachnoid hemorrhage scale: report of a committee of the world federation of neurosurgical societies. J Neurol Neurosurg Psychiatry. 1988:51(11):1457.

37. Teasdale G, Jennett B. Assessment of coma and impaired consciousness. A practical scale. Lancet. 1974;2(7872):81-4.

38. Blijdorp K, Khajeh L, Ribbers GM, Sneekes EM, Heijenbrok-Kal MH, van den Berg-Emons HJ, et al. Diagnostic value of a ghrelin test for the diagnosis of $\mathrm{GH}$ deficiency after subarachnoid hemorrhage. Eur J Endocrinol. 2013:169(4):497-502.

39. World Health Organisation. (2010). Global recommendations on physical activity for health. Retrieved from: http://www.who.int/dietphysicalactivity/ publications/9789241599979

40. Sanchez MC, Bussmann J, Janssen W, Horemans H, Chastin S, Heijenbrok M, et al. Accelerometric assessment of different dimensions of natural walking during the first year after stroke: recovery of amount, distribution, quality and speed of walking. J Rehabil Med. 2015;47(8):714-21.

41. Morris PG, Wilson JT, Dunn L. Anxiety and depression after spontaneous subarachnoid hemorrhage. Neurosurgery. 2004;54(1):47-52; discussion -4.

42. Huenges Wajer IM, Visser-Meily JM, Greebe P, Post MW, Rinkel GJ, van Zandvoort MJ. Restrictions and satisfaction with participation in patients who are ADL-independent after an aneurysmal subarachnoid hemorrhage. Top Stroke Rehabil. 2016:1-8.

43. Shortz AE, Pickens A, Zheng Q, Mehta RK. The effect of cognitive fatigue on prefrontal cortex correlates of neuromuscular fatigue in older women. J Neuroeng Rehabil. 2015;12:115.

44. Paraschiv-lonescu A, Perruchoud C, Rutschmann B, Buchser E, Aminian K Quantifying dimensions of physical behavior in chronic pain conditions. J Neuroeng Rehabil. 2016;13(1):85.

45. Chau JY, Grunseit AC, Chey T, Stamatakis E, Brown WJ, Matthews CE, et al. Daily sitting time and all-cause mortality: a meta-analysis. PLoS One. 2013;8(11):e80000

46. Veldsman M, Churilov L, Werden E, Li Q, Cumming T, Brodtmann A. Physical activity after stroke is associated with increased interhemispheric connectivity of the dorsal attention network. Neurorehabil Neural Repair. 2017;31(2):157-67.

47. Broers NJH, Martens RJH, Cornelis T, van der Sande FM, Diederen NMP, Hermans $\mathrm{MMH}$, et al. Physical activity in end-stage renal disease patients: the effects of starting dialysis in the first 6 months after the transition period. Nephron. 2017;137(1):47-56.

48. van den Berg-Emons RJ, Bussmann JB, Stam HJ. Accelerometry-based activity spectrum in persons with chronic physical conditions. Arch Phys Med Rehabil. 2010;91(12):1856-61.
49. Nieuwenhuijsen $\mathrm{C}$, van der Slot WM, Beelen A, Arendzen JH, Roebroeck ME, Stam HJ, et al. Inactive lifestyle in adults with bilateral spastic cerebral palsy. J Rehabil Med. 2009;41(5):375-81.

50. van den Berg-Emons R, Kazemier G, van Ginneken B, Nieuwenhuijsen C, Tilanus H, Stam H. Fatigue, level of everyday physical activity and quality of life after liver transplantation. J Rehabil Med. 2006;38(2):124-9.

\section{Submit your next manuscript to BioMed Central and we will help you at every step:}

- We accept pre-submission inquiries

- Our selector tool helps you to find the most relevant journal

- We provide round the clock customer support

- Convenient online submission

- Thorough peer review

- Inclusion in PubMed and all major indexing services

- Maximum visibility for your research

Submit your manuscript at www.biomedcentral.com/submit 